\title{
ANÁLISIS MORFOMÉTRICO DE LA VULNERABILIDAD POR EXPOSICIÓN A FLUJOS DE DETRITOS EN LA SUBCUENCA DE LA QUEBRADA HORNILLAS, COSTA RICA, AÑO 2018.
}

MORPHOMETRIC ANALYSIS OF THE VULNERABILITY BY EXPOSURE TO FLOW OF DETRITOS IN THE SUBCUENCA DE LA QUEBRADA HORNILLAS, COSTA RICA, YEAR 2018.

\author{
ANYELA MURILLO ARROYO ${ }^{1}$, NELSON ARROYO GONZÁLEZ ${ }^{2}$ \\ ${ }^{1}$ ANYELA MURILLO ARROYO, INSTITUTO COSTARRICENSE DE ELECTRICIDAD (ICE), \\ GESTIÓN DE INFORMACIÓN GEOGRÁFICA, RECURSOS GEOTÉRMICOS. Bagaces, Costa Rica. \\ anyela.murillo@hotmail.com
}

${ }^{2}$ NELSON ARROYO GONZÁLEZ, ESCUELA DE GEOGRAFÍA, UNIVERSIDAD NACIONAL, Heredia, Costa Rica. nelson.arroyo2008@gmail.com

Recibido: 17 de mayo de 2019 / Aceptado: 20 de junio de 2019

\section{RESUMEN}

El presente estudio evalúa la intensidad de exposición a flujos de detritos en la subcuenca de la quebrada Hornillas, la cual históricamente se ha visto afectada por desprendimientos de material y el descenso de flujos de lodo debido a una morfología, cuyos aportes geológicos predominantes son depósitos de lahar, lavas andesíticas, tobas, depósitos lacustres, así como con un sistema de fallas relacionadas con la Caldera de Mogote y el Volcán Miravalles. Los resultados de la susceptibilidad a flujos de detritos obtenidos en las laderas de la subcuenca al aplicarse el método de Mohr y Coulomb, permitieron relacionar los efectos de las lluvias en las áreas de la subcuenca que recibieron los efectos causados por el Huracán Otto durante el año 2016

Palabras clave: flujos de detritos, susceptibilidad, Volcán Miravalles, modelo Mohr y Coulomb, Huracán Otto..

\begin{abstract}
This study evaluates the intensity of exposure to debris flows in the sub-basin of the Hornillas creek, which historically has been affected by material detachments and the decrease of mudflows due to a morphology, whose predominant geological contributions are deposits of lahar, andesitic lavas, tuffs, lacustrine deposits, as well as a system of faults related to the Caldera de Mogote and the Miravalles Volcano. The results of the susceptibility to flows of detritus obtained in the slopes of the sub-basin when applying the method of Mohr-coulomb, allowed to relate the effects of rains in the sub-basin areas that received the effects caused by Hurricane Otto during the year 2016
\end{abstract}

Keywords: debris flows, susceptibility, Miravalles Volcano, Mohr-coulomb model, Hurricane Otto. 


\section{INTRODUCCIÓN}

La incidencia de fenómenos hidrometereológicos durante los últimos años en el cantón de Bagaces ha dado como resultado un aumento en los incidentes de procesos de remoción en masa, dejando en manifiesto la vulnerabilidad en la que reside la población de las cuencas altas y media de los ríos Blanco, Cuipilapa, Chiquito y Naranjo. (Mapa No.1).

Durante noviembre del 2016, la influencia del Huracán Otto favoreció la formación de deslizamientos, flujos de detritos y de lodo, los cuales durante su desplazamiento de las partes altas a las medias ocasionaron la pérdida de vidas humanas y animales, así como la afectación parcial y total de viviendas, vías de comunicación, servicios básicos, industria agropecuaria, turística, y energética.

Una de las cuencas que se considera sufrió la mayor afectación para el cantón de Bagaces, fue la perteneciente a la quebrada Hornillas. Según Chavarría et al (2017) el flujo de detritos que descendió por este sistema fluvial estaba compuesto de una mezcla caótica de bloques de lava en su mayoría decimétricos hasta de $5 \times 3 \times 2 \mathrm{~m}$, soportados en una matriz fina (40-60\%) de grava, arena y lodo, además de fragmentos de lava, flujos pumíticos, material con alteración hidrotermal y restos de madera; significando un depósito aproximado de $150000-200000 \mathrm{~m}^{3}$.(idem).

No obstante el que para la población del cantón de Bagaces el proceso ocurrido durante noviembre del 2016 era un evento nuevo, gracias a investigaciones como las de Alvarado (2017) y Chavarría et al, (2017), se logró datar al menos cinco acontecimientos similares.

Varios autores entre los que sobresalen Chiesa et al (1992) y Vega et al (2005), describen la geomorfología del Volcán Miravalles como compleja. Tal característica se debe a que es una región constituida por edificios volcánicos que se superponen en una secuencia eruptiva a lo largo de miles de años; coladas de lava y erupciones muy explosivas asociadas con el posible ascenso de la presión de los fluidos, provocando el parcial vaciado de la cámara magmática. Hubo posteriores colapsos caldericos y un sistema estructural de fallas con rumbo N-S y NE-SW y una sismicidad asociada.

En vista de los rasgos morfotectónicos y geomorfológicos asociados al flanco suroeste del Volcán Miravalles así como el crecimiento y desarrollo de las actividades turísticas, residenciales e industriales en las subcuencas altas; se desea evaluar por medio de un Sistema de Información Geográfica, la vulnerabilidad por exposición a flujos de detritos de toda la infraestructura que se localiza en la subcuenca de la quebrada Hornillas. 


\section{MATERIALES Y MÉTODOS}

\section{ÁREA DE ESTUDIO}

La presente investigación tiene como unidad de estudio la subcuenca de la quebrada Hornillas; sistema hidrológico de importancia ambiental y económica para el cantón de Bagaces y la provincia de Guanacaste, debido a su gran valor paisajístico, a la producción de energía geotérmica, así como a las actividades turísticas y la industria ganadera.

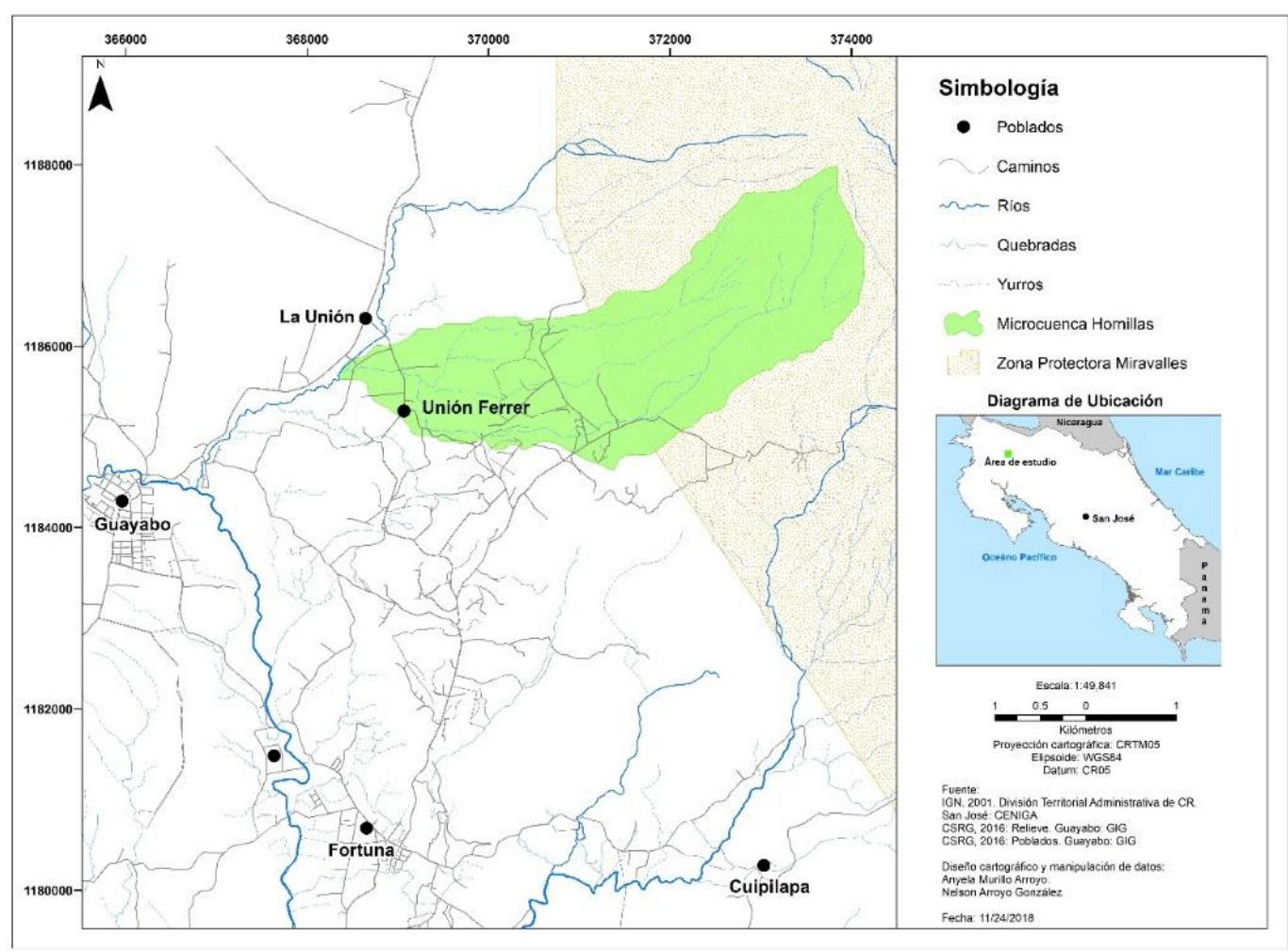

Mapa 1. Área de estudio

Este sistema fluvial se localiza en el flanco suroeste del borde externo de la Caldera de Guayabo. Forma parte de la subcuenca del río Blanco la cual pertenece a la cuenca del río Tempisque. Las coordenadas UTM que la delimitan están dadas en latitud norte por $10^{\circ} 741514$ y en longitud oeste por $85^{\circ} 150665$,

La superficie total de la cuenca es $8.54 \mathrm{~km}^{2}$ y una longitud axial de $6.09 \mathrm{~km}$. Los principales cursos de agua son en su mayoría intermitentes a excepción de las quebradas Hornillas y Herrumbre. El tributario de mayor altitud tiene su nacimiento a 
unos 1897 metros mientras que su confluencia con el río Blanco sucede a unos 557 metros, lo cual evidencia una pendiente media del cauce principal de $17.03 \%$.

\section{Geología}

Este sistema fluvial, desarrollado íntegramente sobre ignimbritas ha modelado una topografía que muestra depresiones alargadas y profundas, propias del modelado fluvial que son aún evidentes dentro de la cobertura boscosa de su cuenca superior. Usualmente las superficies cubiertas de ignimbritas modelan pasos de agua profundos y con valles fluviales con costados de valle verticales. En el caso de la quebrada Hornillas este rasgo es evidente en el curso fluvial de mayor longitud, el cual a raíz de haber canalizado en su momento materiales aportados por deslizamientos, como producto del paso del Huracán Otto (2016), se produjeron ensanches de cauce de 200 metros con estimados de $200 \mathrm{mil} \mathrm{m}^{3}$ de detritos (Murillo, 2017).

En los materiales ignimbríticos por lo general, los cursos fluviales se organizan siguiendo un patrón de drenaje dendrítico lo cual evidencia la homogeneidad de los materiales disectados por los que discurre. Aunque de acuerdo con Madrigal (1980), en algunas secciones se aprecian variaciones hacia patrón rectangular originado por la "presencia de un sistema de fracturas originado al momento de enfriarse y consolidarse la roca (Madrigal, 1090). Los fondos de los valles fluviales son angostos al igual que los interfluvios, en donde tanto la pendiente como lo desagregado de los materiales que conforman el área, evidencia un predominio de la erosión vertical. (Tabla No1).

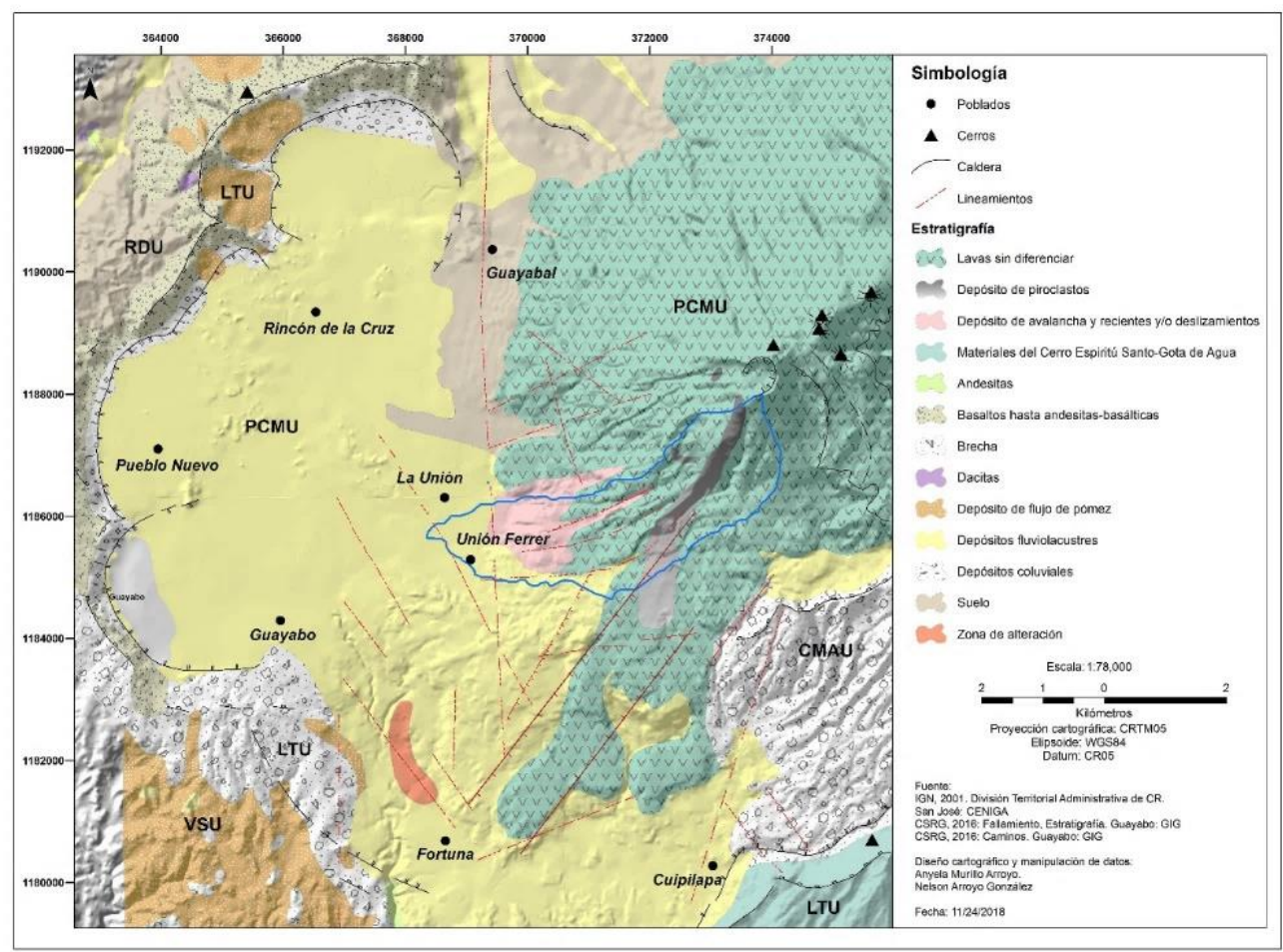




\section{Mapa 2. Geología}

Tabla 1. Secuencia estratigráfica de la Caldera de Guayabo

\section{Unidad}

Unidad de Lavas y Tobas (LTU) Compuesta por lavas y esporádicos depósitos de piroclásticos. Las lavas son predominantemente andesíticas con intercalaciones de tobas, ignimbritas y niveles epiclásticos.

Unidad Volcano-Sedimentario (VSU)

Unidad andesítica Cabro mucho (CMAU)

Unidad Post Cabro Muco (PCMU)

Unidad de Depósitos Recientes
Esta unidad incluye flujos piroclásticos pumíticos, tobas, depósitos epiclásticos y depósitos lacustres.

Incluye lavas andesítico-basálticas, como flujos de tobas líticas. Esta unidad está asociada a colapsos, explosiones volcánicas, erosión y tectonismo.

Esta unidad está formada principalmente por lavas andesítico-basálticas con esporádicos depósitos de piroclástos, así como flujos de debris avalanche, lahares y depósitos lacustres.

Esta unidad incluye grandes capas de suelo formados por fragmentos de lava del borde de la caldera.

Fuente: Vega et al. (2005)

A nivel estructural en la zona predomina un fallamiento N-S y NE-SW de tipo normal con probable componente de rumbo, el cual originó un sistema escalonado de fallas tipo graben, produciendo un desplazamiento morfológico vertical especialmente en el borde norte de la Caldera Guayabo. Otros rasgos volcano-tectónicos importantes de la región son la presencia de actividad volcánica de tipo secundario como solfataras, batideros de lodo y fuentes termales (Vega et al., 2005) (Mapa No.2).

\section{Clima}

La subcuenca presenta en una parte considerable de su territorio, un microclima tropical húmedo a muy húmedo, el cual es muy característico de las zonas de transición entre las masas de aire cálido provenientes del Caribe y las tierras a sotavento. La precipitación promedio anual es de $3500 \mathrm{~mm}$, mientras que la humedad relativa es del $85 \%$. La temperatura ronda de $\operatorname{los} 18$ a $\operatorname{los} 28^{\circ} \mathrm{C}$ (INA, 2005, Vargas, 2008 y Murillo, 2017).(Mapa No3). 


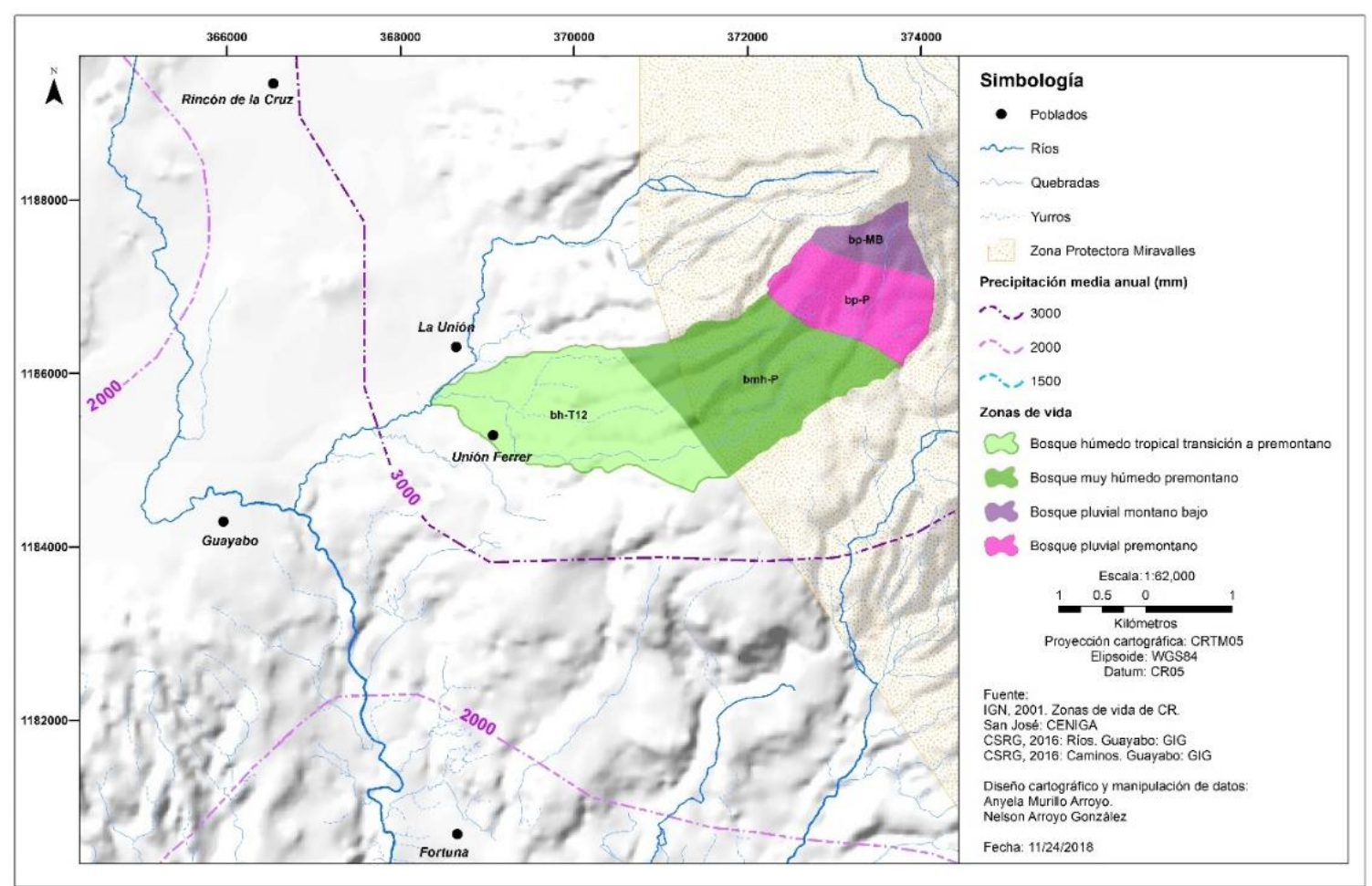

Mapa 3. Zonas de vida

\section{Coberturas}

En cuanto a las coberturas y usos de la tierra, en la cuenca predominan mayoritariamente las actividades agropecuarias, las cuales son características de la llanura aluvial o subcuenca baja. En la región montañosa sobresalen las coberturas forestales asociadas a la Zona Protectora Miravalles, así como algunos potreros en proceso de regeneración natural, la infraestructura asociada a la industria geotérmica y turística.

\section{MATERIALES}

Para la realización de este trabajo de investigación se utilizaron imágenes satelitales provenientes de los sensores WorlView-3 y Sentinel 2A. De estos sensores se extrajeron los modelos de elevación digital, así como cartografía base para las modelaciones de la estabilidad de laderas o q/t y el cálculo de los parámetros morfométricos.

También se contó con material cartográfico auxiliar correspondiente a coberturas vectoriales de diferentes organismos públicos como, por ejemplo, la red hídrica superficial, poblados, vías de comunicación, curvas de nivel y límites administrativos. La Tabla 1 describe los principales insumos utilizados para la investigación. (Tabla No,2). 
Tabla 2. Fuentes primarias de información utilizadas en la investigación

\begin{tabular}{|c|c|c|c|}
\hline Nombre & Formato & Escala & Fuente \\
\hline Poblados & Features class & $1: 5000$ & IGN. 2014 \\
\hline Curvas de nivel & Features class & $1: 5000$ & IGN. 2014 \\
\hline Red hídrica & Features class & $1: 5000$ & $\begin{array}{l}\text { Murillo, A. 2018; } \\
\text { propios de la } \\
\text { investigación }\end{array}$ \\
\hline Vías de comunicación & Features class & $1: 5000$ & CSRG. 2017 \\
\hline $\begin{array}{l}\text { Zonas de } \\
\text { desprendimiento }\end{array}$ & Features class & $1: 5000$ & Murillo, A. 2018 \\
\hline Afectaciones Otto & Features class & $1: 1000$ & CSRG, 2017 \\
\hline WorldView-3 & Raster & $5 \mathrm{~m}$ & CSRG, 2017 \\
\hline Sentinel 1A SLC & Raster & $2.7 \times 22 \mathrm{~m}$ & $\begin{array}{l}\text { Vertex del Alaska } \\
\text { Satellite Facility }\end{array}$ \\
\hline Sentinel 1B SLC & Raster & $2.7 \times 22 \mathrm{~m}$ & $\begin{array}{l}\text { Vertex del Alaska } \\
\text { Satellite Facility }\end{array}$ \\
\hline
\end{tabular}

Fuente: Elaboración propia para la investigación

\section{SOFTWARE UTILIZADO}

Se utilizaron los siguientes Sistemas de Información Geográfica:

- Global Mapper v18

- ArcView 3.2

- Saga GIS 2.18

- ArcGIS v10.6.

\section{MÉTODOS}

\section{ESTABILIDAD DE LADERAS (SHALSTAB)}

Este modelo es una combinación de componentes hidrológicos y geomecánicos, que definen el grado de saturación y el ángulo de fricción necesario para desestabilizar una ladera. Está basado en la siguiente ecuación:

$$
\frac{h}{Z}=\frac{P s}{p}\left(1-\frac{\tan \theta}{\tan \emptyset}\right)
$$

En donde:

$\boldsymbol{h}=$ representa la altura del nivel freatico sobre la superficie de deslizamiento.

$z=$ la profundiad del suelo

ps $=$ densidad del suelo

$\boldsymbol{p}=$ densidad del agua 


\section{$\tan \theta=$ pendiente de la ladera}

$\varnothing=$ ángulo de fricción interna

El índice de estabilidad se expresa en mm día de lluvia crítica y es variable en una escala de valores, donde los más bajos indican una mayor propensión a la inestabilidad y los más altos una mayor propensión a la estabilidad (Zizioli, Meisina, Valentino y Montrasio, 2013).

El proceso metodológico para obtener los valores de estabilidad consistió en la generación de un modelo de elevación digital del terreno (MDE), del cual se derivaron los mapas de pendientes, acumulación y por consiguiente el de estabilidad de laderas.

El MDE se generó en el Sistema de Información Geográfica ArcGIS 10.6, utilizando la función Topo to Raster, ya que este tipo de interpolación garantiza una estructura de drenaje conectado y la correcta representación de crestas y arroyos a partir de los datos de entrada (ESRI, 2018).

Una vez finalizado este proceso se procedió a generar las cuencas y la red de drenaje en el Sistema de Información Geográfica Global Mapper v18, ya que el algoritmo de dicho software genera cauces más suavizados y define mejor los límites de las cuencas hidrográficas.

Los parámetros de entrada definidos para la generación de las cuencas fueron los siguientes: (Figura No1).

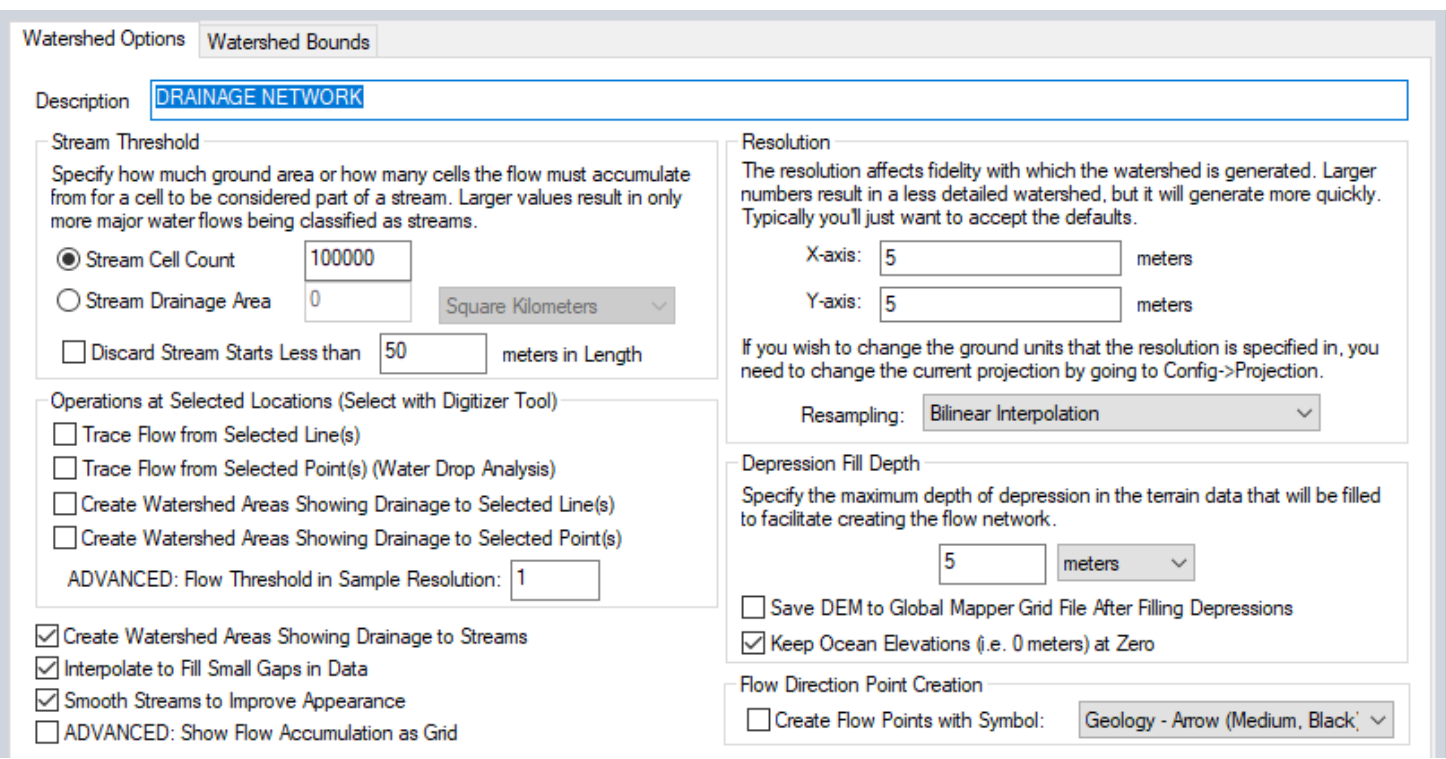

Figura 1. Datos de entrada en el Global Mapper v18 para la generación de las cuencas y red de drenaje 
El tamaño de la celda definido fue de 100000 unidades, ya que se requería que el software generalizara las cuencas, permitiendo identificar la correspondiente a la quebrada Hornillas y su cauce principal.

Definida el área de estudio, se procedió a calcular en el Sistema de Información Geográfica ArcView 3.2, los valores de estabilidad de laderas, para lo cual se siguió el siguiente procedimient0: (Figura No.2)

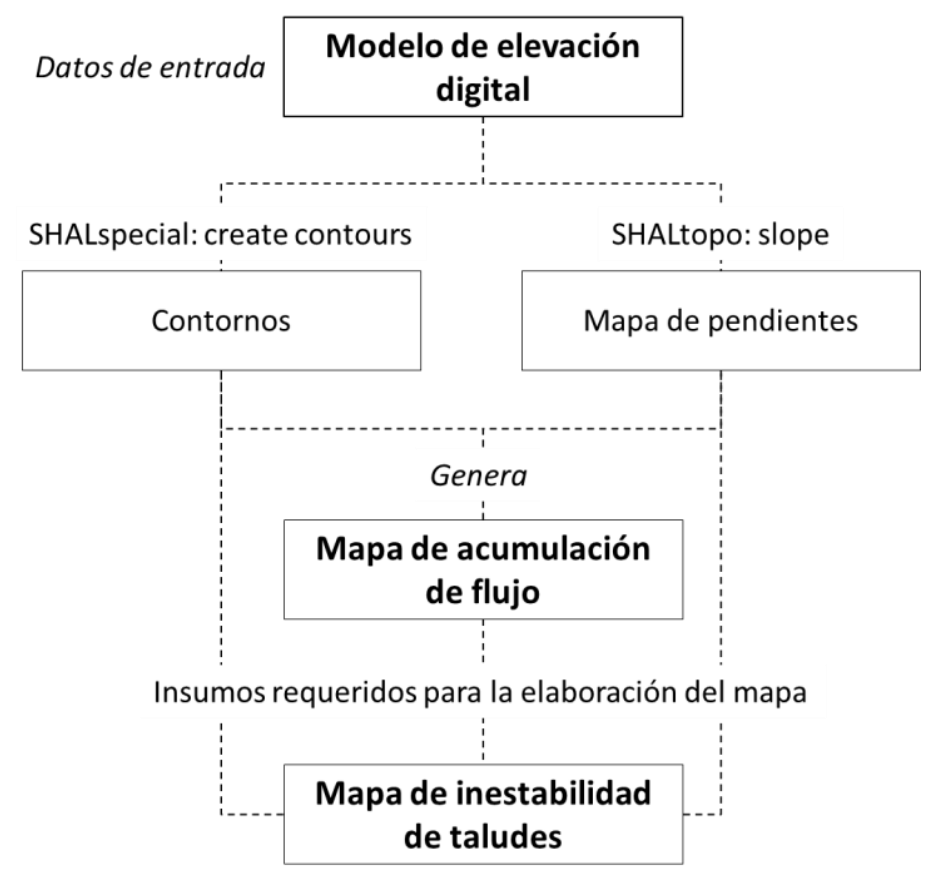

Figura 2. Herramientas utilizadas para generar el mapa de inestabilidad de taludes

Los principales insumos requeridos para la definición del mapa de $q / t$ son las pendientes, los contornos o curvas de nivel y la acumulación de flujo. Dentro del SHALSTAB hay varias herramientas que permiten obtener los insumos requeridos para el cálculo del índice de $q / \mathrm{t}$ como SHALspecial la cual se utiliza para calcular los contornos requeridos para definir las pendientes y SHALtopo utilizada para generar los mapas de taludes/laderas (dados en porcentajes) y el de acumulación de flujo o $a / b$.

Una vez obtenidos estos productos, se procede a elaborar el mapa de estabilidad de taludes, seleccionando y añadiendo todas las capas creadas con anterioridad en la herramienta $q / t$ from slope and area grids, la cual genera un ráster con valores de estabilidad de laderas.

El ráster generado fue cargado en el Sistema de Información Geográfico ArcGIS 10.6 para la aplicación del método Algebra de Mapas (Raster Calculator) y la elaboración de la salida cartográfica del estudio. 


\section{MORFOMETRÍA}

Este procedimiento analiza las relaciones espaciales que caracterizan a las formas del terreno, con el fin de delimitar la fisiografía según sus relaciones con otros componentes del paisaje (Gilsanz, 1996). Para el cálculo de los parámetros morfométricos se utilizó el Sistema de Información Geográfica Saga GIS 2.3.2 y las herramientas Geoprocessing/Basic Terrain Analyst para obtener los valores de Topographic Wetness Index (TWI) y LF Factor.

El proceso metodológico seguido fue el siguiente: (Figura No.3).

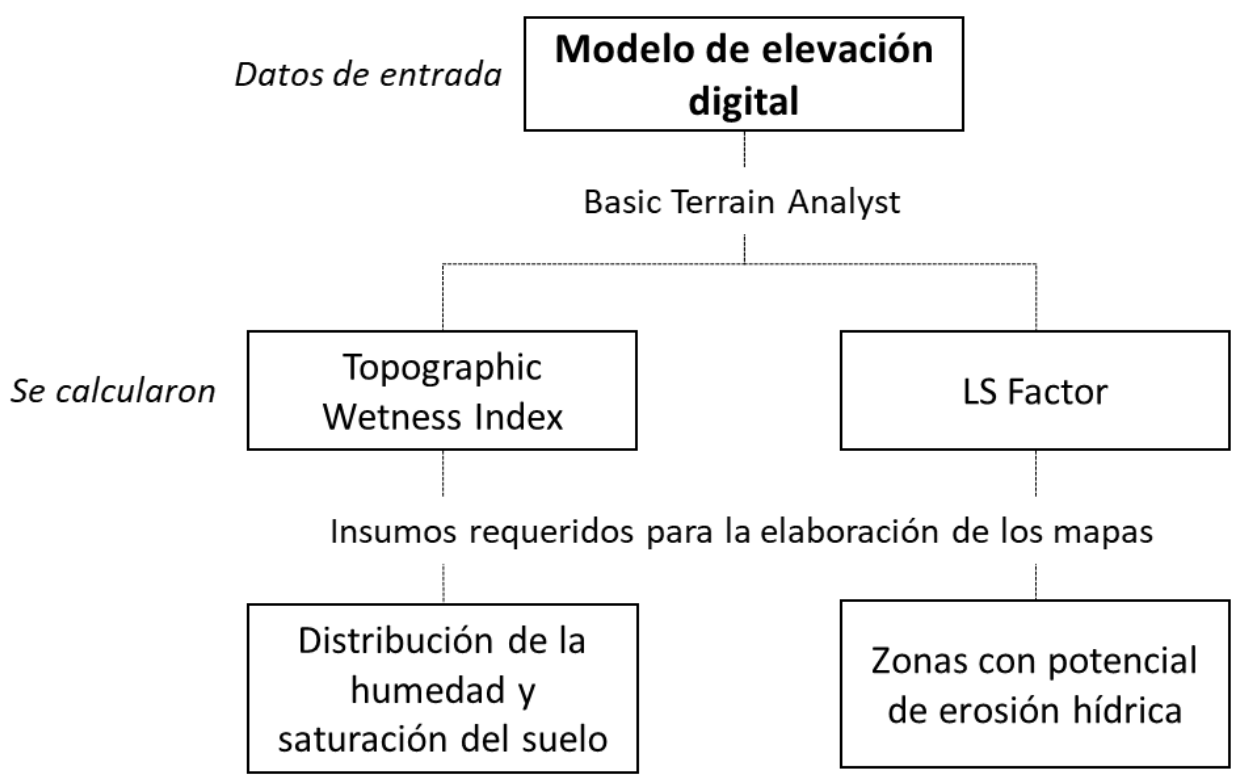

Figura 3. Proceso metodológico seguido.

Fuente: Elaboración propia para la investigación

El índice de humedad topográfica o TWI se utiliza para cuantificar el control de la topografía en los procesos hidrológicos e indicar la espacialidad de la humedad del suelo y la saturación de la superficie, permitiendo representar la tendencia de una celda para producir escorrentía considerando que un área con mayor humedad es más propensa a saturarse.

Para el caso del LS Factor o factor de pérdida de suelo, este índice permite identificar las zonas con mayor potencial de erosión hídrica, las cuales se consideran áreas con mayor riesgo de deslizamientos.

\section{RELACIONES DE INESTABILIDAD}

Para este proceso se utilizó el método heurístico, el cual evalúa las condiciones de estabilidad de un área dada considerando una gran cantidad de factores y su 
combinación. Para esta investigación se correlacionaron los valores de $q / t$ con los mapas de TWI, Ls Factor y $a b$, a través de operaciones matriciales de suma, resta, multiplicación y división con el fin de obtener la mejor relación de inestabilidad de laderas del área de estudio. La validación de este proceso se realizó a través de la identificación de rasgos comunes entre todos los mapas obtenidos y el inventario de deslizamientos del periodo 2005-2018 y el mapa de pendientes.

El proceso metodológico utilizado fue el siguiente: (Figura No.4).

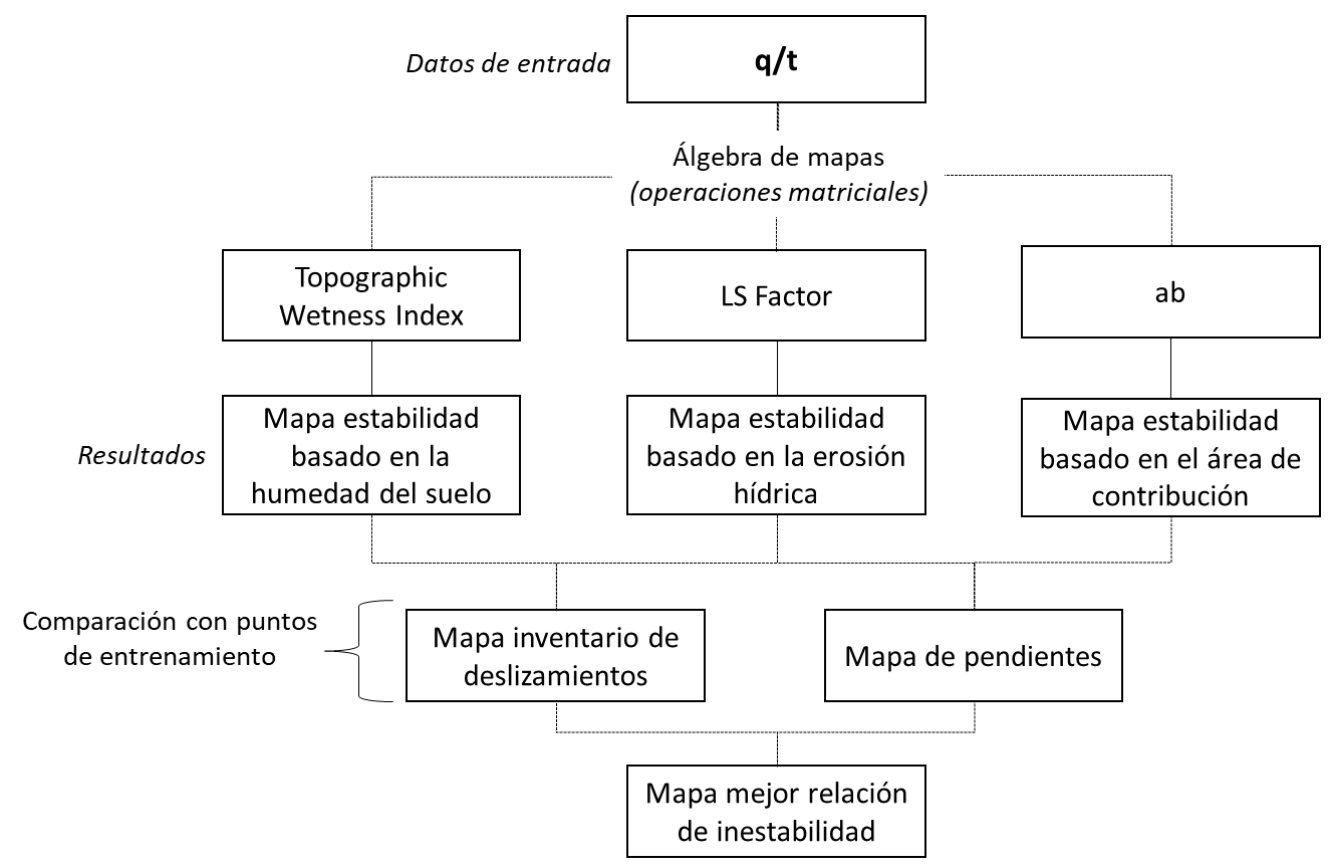

Figura 4. Proceso metodológico seguido.

Fuente: Elaboración propia para la investigación

\section{MAPA DE INTENSIDAD DE EXPOSICIÓN A AMENAZAS MORFOLÓGICAS}

Se utilizo el Sistema de Información Geográfico QGIS 2.18 y la herramienta INASAFE para generar un modelo de evaluación de riesgos de tipo determinístico en la subcuenca Hornillas, permitiendo identificar el tipo de exposición de la infraestructura residencial, turística e industrial ante amenazas morfológicas como deslizamientos, flujos de detritos, lodo e inundaciones.

Para este proceso se realizó una reclasificación del mapa de zonas inestables en función de la erosión hídrica, ya que se requería contar con un ráster de entrada que definiera las 4 clases de vulnerabilidad existentes en la cuenca.

Las categorías definidas fueron las siguientes: (Tabla No.3). 
Tabla 3. Escala de valoración del mapa de zonas inestables en función de la erosión hídrica

\begin{tabular}{ccl}
\hline Escala & Categoría & \multicolumn{1}{c}{ Descripción } \\
& Baja & $\begin{array}{l}\text { Son aquellos terrenos cuya condición morfológica se considera } \\
\text { estable, con pendientes que van desde las llanas a ligeramente } \\
\text { onduladas, representando un peligro bajo para la cuenca. }\end{array}$ \\
& $\begin{array}{l}\text { Son aquellos terrenos que esporádicamente se han visto afectados } \\
\text { por inundaciones y/o acumulación o propagación de agua, debido a } \\
\text { la incidencia de rasgos morfológicos como la pendiente, litologías } \\
\text { poco permeables y colmatación de cauces. }\end{array}$ \\
& $\begin{array}{l}\text { Son aquellos terrenos que presentan condiciones de inestabilidad de } \\
\text { laderas altas, producto de sus rasgos morfológicos y la incidencia de } \\
\text { agentes disparadores como la precipitación, humedad del suelo y la } \\
\text { sismicidad. }\end{array}$ \\
Muy alta & $\begin{array}{l}\text { Son aquellos terrenos que presentan una condición crítica debido a } \\
\text { sus rasgos morfológicos (fuertes pendientes, litologías con baja } \\
\text { capacidad de cohesión, humedad del suelo, fuertes precipitaciones y } \\
\text { sismicidad). }\end{array}$ \\
\hline
\end{tabular}

Fuente: Elaboración propia para la investigación

Posterior a este proceso se procedió a correlacionar las variables vulnerabilidad e infraestructura para obtener el mapa de tipo de exposición.

El proceso metodológico utilizado fue el siguiente; (Figura No.5).

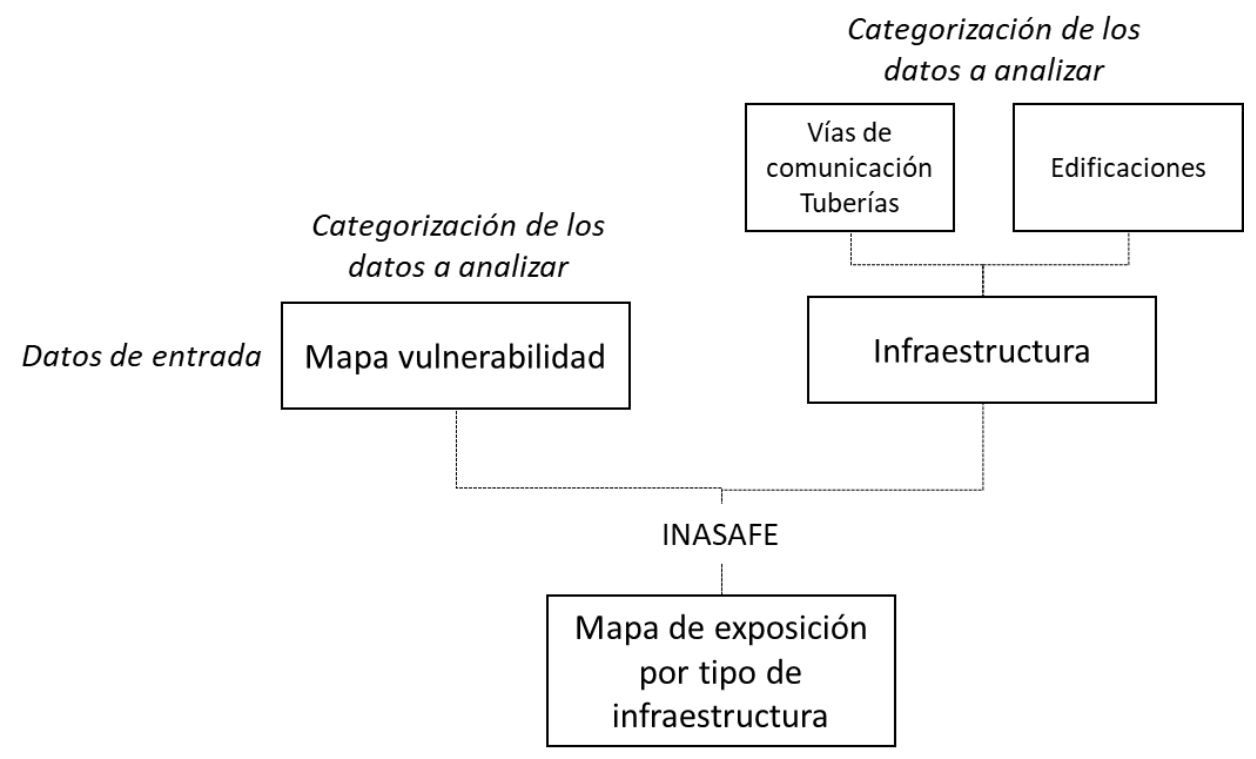

Figura 5. Proceso metodológico seguido.

Fuente: Elaboración propia para la investigación 


\section{RESULTADOS}

A continuación, se presentan los principales resultados obtenidos de la investigación:

\section{MAPA DE ESTABILIDAD DE LADERAS o $q / t$}

El área de estudio presenta una condición de inestabilidad muy alta debido a su morfología, ya que predomina un nivel alto de saturación del suelo, fuertes pendientes, poca cohesión y meteorización de los materiales litológicos, así como presencia de alteración hidrotermal, fuertes vientos y una alta sismicidad. (Mapa No.4).

Durante los años 2016 y 2017, el aumento de la precipitación producto de los eventos hidrometereológicos Otto y Nate, influyeron drásticamente en la aparición de deslizamientos de tipo regolíticos en la cuenca alta, los cuales fueron drenados por los cauces principales ocasionando incidentes por descenso de flujos de lodo y detritos en la parte baja de la quebrada Hornillas.

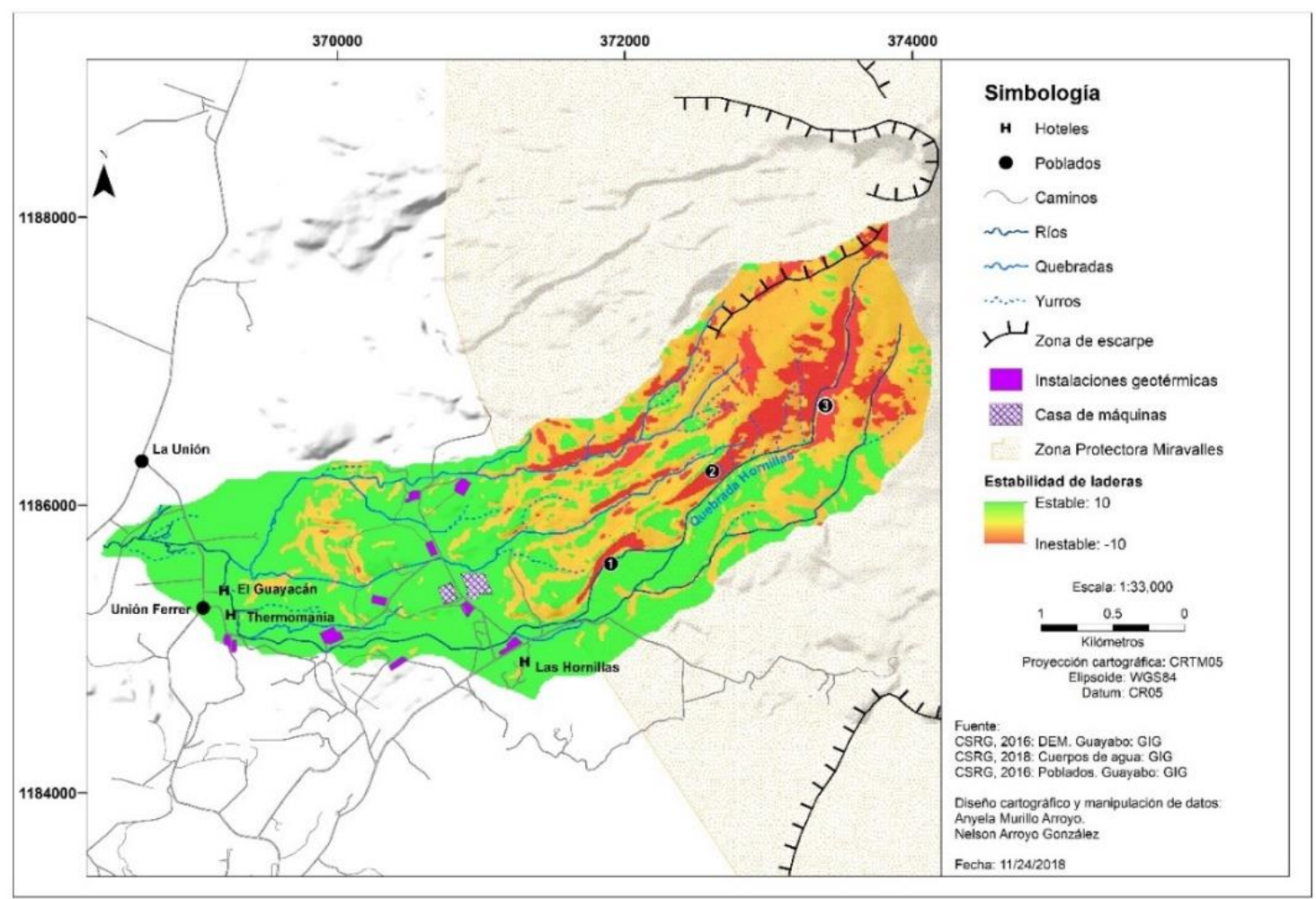

Mapa 4. Mapa de estabilidad de laderas

Según el mapa obtenido, la cuenca alta es la que presenta los mayores valores de susceptibilidad, debido a las fuertes pendientes, a los materiales predominantes (suelos arenosos) y a la acumulación máxima de flujo; siendo los principales: el cauce de la quebrada Hornillas (cauce con mayor pendiente del área de estudio) y los taludes cercanos a las trazas de fallas en la subcuenca media. Como puede observarse, en la 
sección alta de la cuenca no existen centros poblados u otro tipo de instalaciones; situación que sí acaece en la parte baja o de depósito. Por ende, los flujos de material con origen en las tierras altas concentran efectos nocivos en los sectores bajos. (Mapa No.4).

Como resultado el modelo identifica en un inicio las celdas incondicionalmente estables e inestables, en las cuales su estabilidad es independiente de las condiciones de lluvia. Y para la lluvia analizada el modelo señala las celdas inestables y que fallarían ante dicho evento de lluvia así como las celdas que permanecen estables.
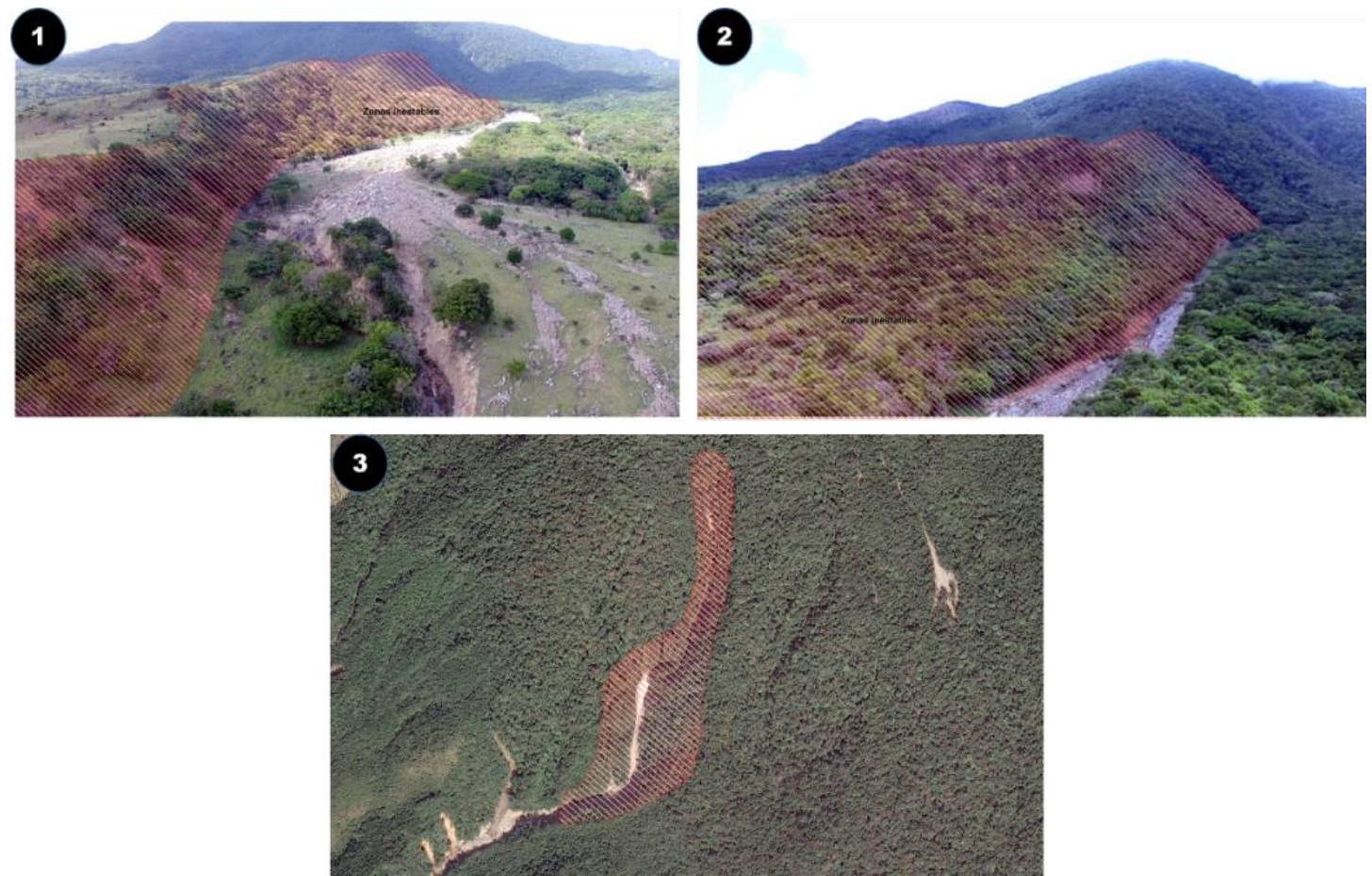

Figura 6. Condición de inestabilidad de la cuenca de estudio

En las fotografías anteriores se aprecian claramente los efectos de la erosión y el transporte del material, provenientes precisamente de los costados de valles fluviales de pendiente fuerte, así como el acúmulo cuantioso que en la fotografía número 1, introduce en el cauce mayor del río, una forma de relieve plana inclinada que en función del relleno continuo, colmata un valle en $\mathrm{V}$, típico del sector montañoso en uno con fondo plano. (Figura No.6).

\section{MORFOMETRÍA}

Se analizaron los índices de TWI y LS Factor:

El índice de TWI o humedad del suelo muestra que el control topográfico en procesos hidrológicos es relevante, ya que, al estar en función de la pendiente, se observa como en las áreas planas y plano inclinadas se presenta una acumulación de humedad. 
Según el mapa No.5 se observan pequeños sectores al sur del poblado La Unión, así como secciones de coloraciones rojizas cercanas a instalaciones geotérmicas que muestran coloraciones rojizas. Ello puede originarse probablemente a su condición alargada similar a cursos fluviales y que pudiera asociarse a índices de humedad altos, con asocio a atributos del suelo como el porcentaje de limo y el contenido de materia orgánica.

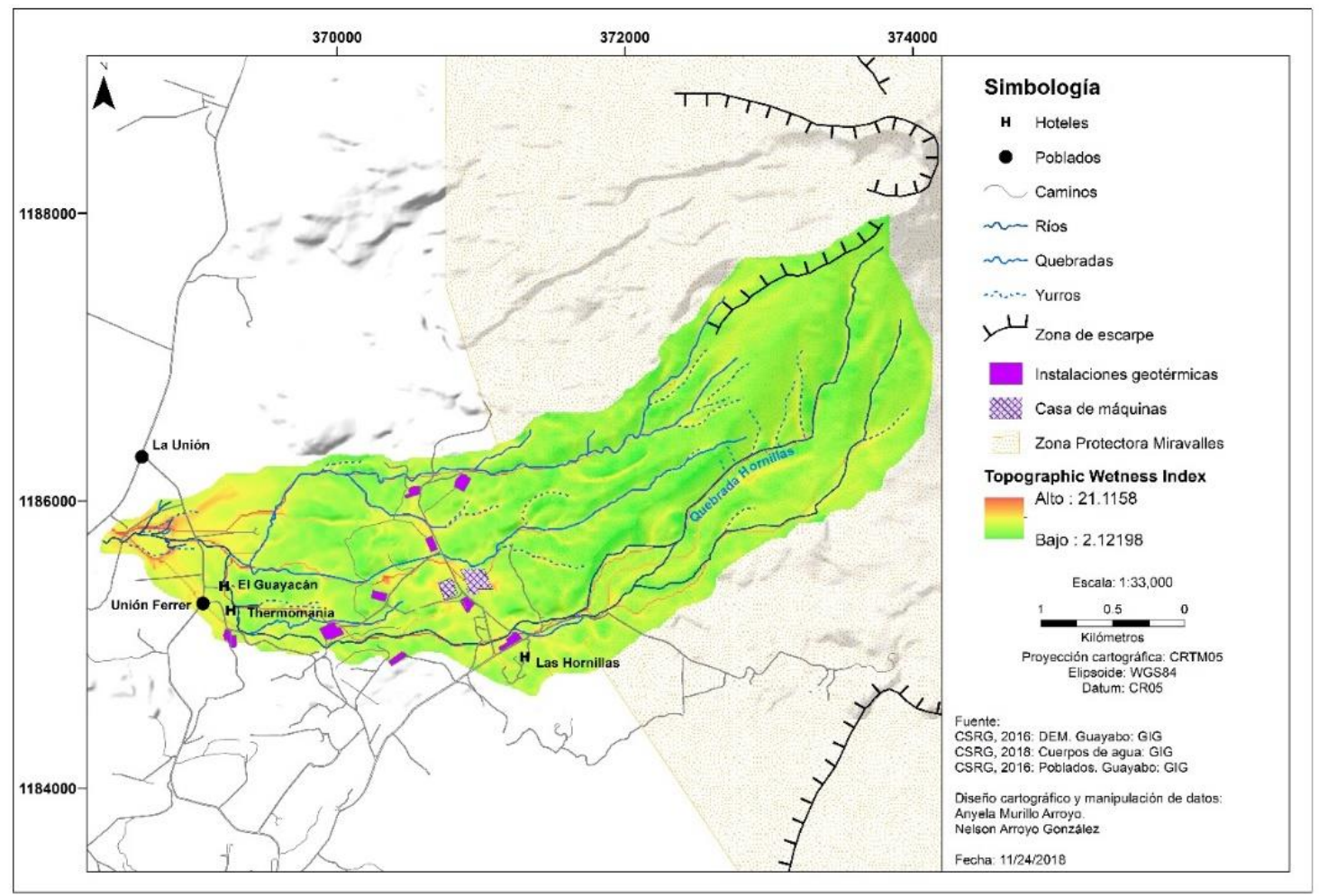

Mapa 5. Mapa de índice de humedad del suelo

El mapa de erosión hídrica (Mapa No.6) en principio es congruente con la topografía del área. Así las áreas con coloración rojiza indican pérdida de suelo, o lo que es casi igual afirmar que son sectores sujetos a la erosión. Lógicamente estos territorios se localizan en la sección de la cuenca que posee las pendientes más fuertes hacia el borde sur de la caldera de Miravalles, así como en las áreas adyacentes a cursos fluviales y en las cuales el proceso de escorrentía es dominante. La correspondencia que se establece entre estos sectores abruptos y el material desagregado producto de episodios de depositación ya sea aérea o por flujos de detritos, delimita extensiones amplias, así como franjas alargadas que se corresponden a los costados de valle fluviales. El descenso hacia las tierras más bajas y la disminución del grado de pendiente muestra como la erosión gradualmente va disminuyendo tal y como lo muestra la coloración verde. 


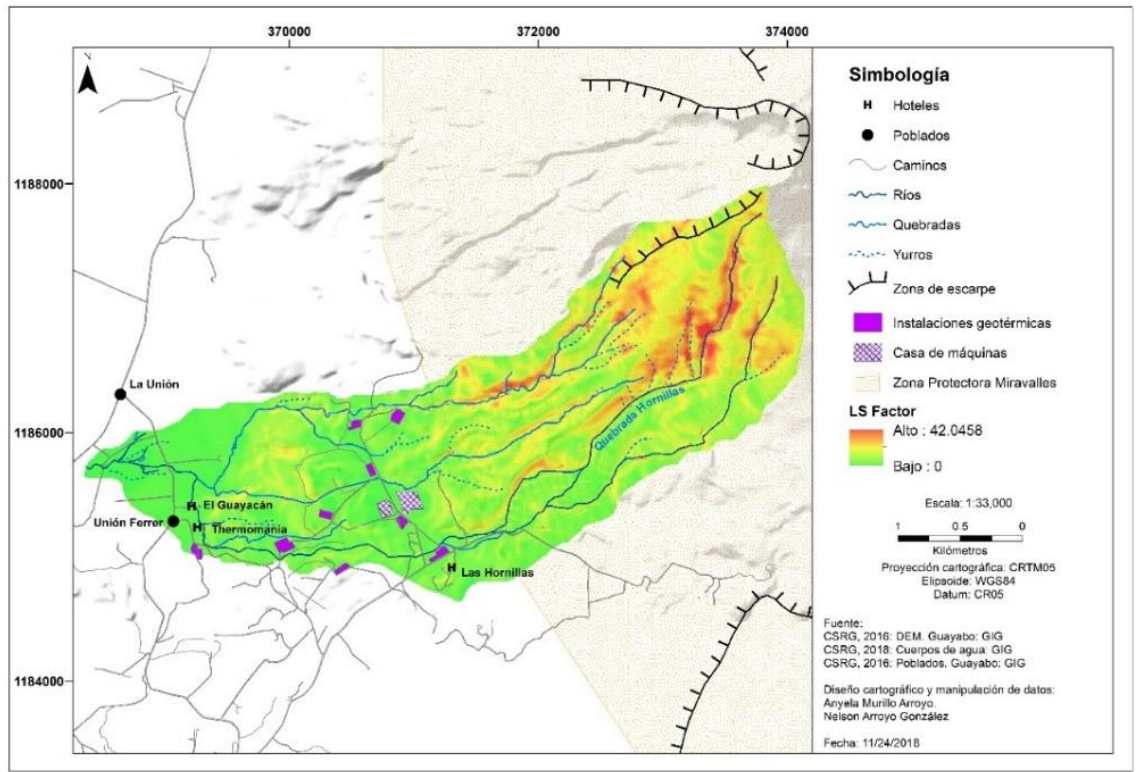

Mapa 6. Mapa de erosión hídrica

\section{MAPA DE ZONAS INESTABLES EN FUNCIÓN DE LA EROSIÓN HÍDRICA}

Los valores altos negativos, de color rojizo indican mayor inestabilidad de taludes. Aquí existe una estrecha relación entre el grado de pendiente y la inestabilidad de terrenos. Así la combinación de pendientes fuertes, erosión acentuada y materiales geológicos desagregados, establecen zonas de inestabilidad y por ello, sectores susceptibles de deslizarse. (Mapa No.7).

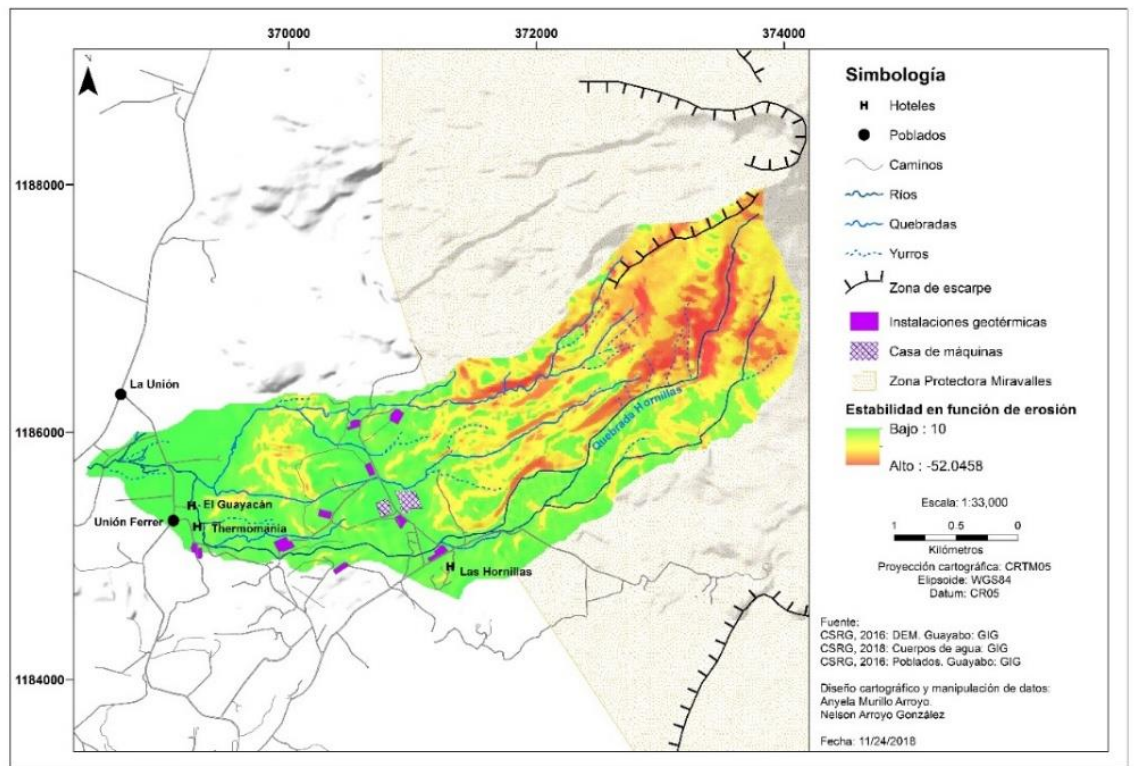

Mapa 7. Mapa de zonas inestables en función de la erosión hídrica 
En el mapa anterior se aprecia como las áreas inestables se amplían a partir de la sección alta de la cuenca, desplazándose hacia terrenos que se corresponden con la dirección de flujo de los materiales. La presencia de sectores inestables más en detalle se establece siguiendo un patrón que es concordante con las secciones fluviales que muestran mayor erosión vertical ya que se disponen en correspondencia con dichos trazados fluviales.

\section{MAPA DE EXPOSICIÓN}

Debido a la forma de la cuenca, toda la infraestructura presenta un grado de exposición crítico ya que la ubicación de estos desarrollos se halla en correspondencia con las zonas de depositación de flujos de detritos. (Mapa No.8) (Tabla No.4).

Tabla 4. Características de la infraestructura expuesta

\begin{tabular}{|c|c|c|}
\hline Tipo & Área (ha) & Características \\
\hline Residencial & 1.13 & $\begin{array}{l}\text { Las residencias localizadas en la cuenca son de tipo unifamiliar. } \\
\text { Incluye toda la infraestructura relacionada a la misma. }\end{array}$ \\
\hline Turístico & 1.43 & $\begin{array}{l}\text { Incluye toda la infraestructura relacionada a esta industria como } \\
\text { cabinas, restaurantes, piscinas, ranchos y canopy. } \\
\text { Incluye toda la infraestructura asociada al Campo Geotérmico }\end{array}$ \\
\hline Industrial & 13.5 & $\begin{array}{l}\text { Alfredo Mainieri Protti como pozos, líneas de tuberías, } \\
\text { estaciones separadoras, línea de alta tensión y las unidades } \\
\text { generadoras. }\end{array}$ \\
\hline Comunal & 0.10 & Dentro de la cuenca se localiza una escuela. \\
\hline
\end{tabular}

(18)


Mapa 8. Mapa de exposición

\section{DISCUSIÓN}

La metodología propuesta permitió determinar la susceptibilidad en la que se encuentra la infraestructura que se localiza en la subcuenca Hornillas, obteniendo una escala de exposición, la cual junto con las políticas territoriales correctas pueden restringir y direccionar el crecimiento urbano y turístico en zonas de alto riesgo. (Mapa No.9). Las diferentes herramientas de software empleadas se ajustaron a los parámetros de esperables en esta área, habida cuenta de las restricciones de acceso que el sector presenta. La nitidez de los detalles obtenidos mediante la aplicación de las diferentes etapas de análisis, permite destacar el extraordinario aporte que se muestra mediante la cartografía resultante. Tal aporte resultaría impensable si se hubiese recurrido a técnicas tradicionales de trabajo tales como la elaboración de bocetos mediante análisis manual. La precisión obtenida así como la profusión de detalle en sitios considerados inaccesibles si se hubiera requerido trabajo de campo arduo, no alcanzaría lo prolijo de la información que se aporta. La calidad de los despliegues cartográficos incluidos reside obviamente también no solo en la disponibilidad de información base de alta calidad, tanto por su acervo técnico así como por el entrenamiento profesional de los participantes por cuanto sobre la marcha de la investigación, se requirió de ajustes de acuerdo a los productos gráficos primarios. Es evidente que la información aportada representa un insumo de valor cuando de planificar ocupaciones de territorios se trate, ya que con las técnicas apropiadas, se puede disponer de información especializada y confiable para la toma de decisiones que requieren plazos perentorios.

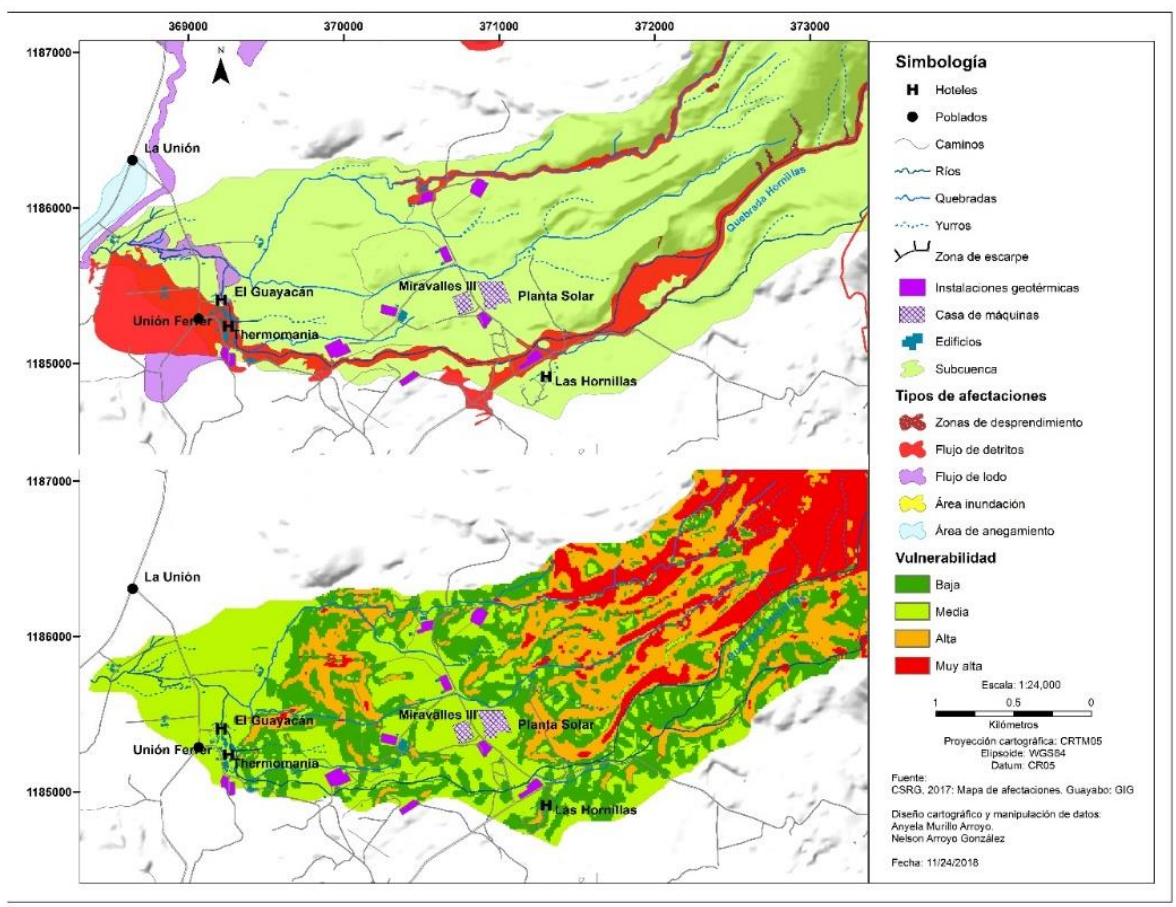


Mapa 9. Comparación de las afectaciones ocasionadas por eventos hidrometereológicos y el mapa de vulnerabilidad

Existe una fuerte relación entre la vulnerabilidad media, alta y muy alta y las áreas que se vieron afectadas por el Huracán Otto. El cauce principal de la cuenca es el que presenta una condición crítica debido a sus rasgos morfológicos.

Las zonas de desprendimiento de detritos (color rojo) muestran un patrón de desplazamiento alargado, que parece ser compatible con el paso de valles fluviales. En el mapa de vulnerabilidad dichas zonas están calificadas como altas y muy altas. También se aprecian sectores con flujos de lodo que también se hallan en correspondencia con depresiones del terreno. Sin embargo, los sectores que exhiben alta y muy alta vulnerabilidad (rojo y anaranjado) no se concentran en forma homogénea a lo largo de los pasos de los flujos y que se muestran arriba. Tales categorías se concentran de preferencia en la sección alta de la cuenca y en una zona que parece hallarse aislada en la parte baja.

Las categorías baja y media muestran correspondencia con las secciones de menor pendiente y por ende, ocupan los sectores de la cuenca baja de preferencia. Estas categorías no parecen asociarse a trayectorias de cursos fluviales, sino que, por su disposición en pequeños y dispersos promontorios, parecen obedecer a acumulaciones finales de materiales provenientes de avalanchas o episodios súbitos. Incluso la vulnerabilidad baja muestra una apariencia que converge en forma de ápice con orientación transversal hacia cursos fluviales como puede observarse al sur de Miravalles III y al este de la Planta Solar. Estas áreas por su categoría baja es probable que se hallen a mayor altitud que los terrenos circundantes, factor que de hecho protege lo que allí pudiera existir. Ello se refuerza al observar que las tierras de vulnerabilidad media prácticamente rodean casi todas las delimitaciones conceptuadas como bajas.

\section{CONCLUSIONES}

El estudio permitió entender de mejor manera los eventos del 24 de noviembre del 2016 con el paso del huracán Otto, hallando el porqué de la gran susceptibilidad a flujos de detritos en la cuenca de la quebrada hornillas, es necesario que este estudio sea profundizado y replicado en las demás subcuencas del Rio Blanco y que las instancias gubernamentales los aprovechen como insumos para la planificación territorial y la construcción de obras de prevención.

Las herramientas SIG utilizadas para los procesamientos de la información fueran muy valiosas en todo el proceso, ya que de una manera muy cercana a la realidad permitieron modelar certeramente los niveles de vulnerabilidad y exposición de la infraestructura a los flujos de detritos, eventos de gran reincidencia en la zona. 


\section{REFERENCIAS}

Alvarado, G. 2017. El Huracán Otto en el Volcán Miravalles. Particularidades, frecuencia, efectos y medidas de mitigación. OSIVAM. San José: ICE

Chavarria, L. 2003. Miravalles Geothermal Field, Costa Rica-evidence of thermal evolution and a comparison of The mineralogy of an acid well and a neutral well. Geothermal Training Programme. Reykjavík: Islandia

Chiesa et al. 1992. Rocas piroclásticas asociadas con la formación de la Caldera Guayabo, Coordillera de Guanacaste, Costa Rica. Revista Geológica de América Central, 14:59-75, 1992

Comisión Nacional de Prevención de Riesgos y Atención de Emergencias. Investigación y Análisis de Riesgo (CNE). 2003. Mapa de Amenazas Naturales del Cantón de Bagaces. Pavas: Costa Rica

Chavarría et al. 2017. Mapa Afectaciones Eventos Hidrometereológicos Otto y Nate. Bagaces: Costa Rica.

ESRI. (2018). Como funciona de Topo to raster. Consultado en: https://pro.arcgis.com/es/pro-app/tool.

Instituto Nacional de Aprendizaje (INA). 2005. Historia Natural de Costa Rica. San José: Costa Rica

Murillo, A. (2017). Identificación de áreas críticas para la adaptación del cambio climático: El caso de la cuenca alta del Río Blanco de Bagaces, Costa Rica. Bagaces: ICE

Vargas, G. (2008). Fragmentación y conectividad de ecosistemas en el sector del proyecto geotérmico Miravalles y sus alrededores, 1975 -2007. En Revista Reflexiones 2008, (Ed). ISSN. pp. 9-37

Vega et al. (2005). Geologic Model of The Miravalles Geothermal Field, Costa Rica. En World Congress 2005, (Ed). Antalya: Turkey. pp 24-29

Zizioli, D; Meisina, C; Valentino, R y Montrasio, L. (2013). Comparison between different approaches tomodeling shallow landslide suceptbility; a case history in Oltrepo Pavese, Northern Italy. Natural Hazard and Earth System Sciences. 